\section{The influence of fear of falling on orthostatic postural control: a systematic review}

\author{
Nélio Silva de Souza,1,2 \\ Ana Carolina Gomes Martins, 1,3 \\ Dângelo J.A. Alexandre, 4 \\ Marco Orsini, 2,5 \\ Victor Hugo do Vale Bastos, 2,6,7 \\ Marco Antônio A. Leite, 8,9 \\ Silmar Teixeira, ${ }^{10-12}$ Bruna Velasques, 12,13 \\ Pedro Ribeiro,12,13 Juliana Bittencourt, 12 \\ André Palma da Cunha Matta, 6 \\ Pedro Moreira Filho6 \\ 1University Center Serra dos Órgãos, \\ Teresópolis; 2Science of Rehabilitation, \\ Centro Universitário Augusto Motta, Rio \\ de Janeiro; 3Integrated Health of Women \\ and Children, Fluminense Federal \\ University, Niterói; 4Public Health, \\ Fundação Oswaldo Cruz, Rio de Janeiro; \\ 5 Severino Sombra University Center, \\ Medicine Department, Vassouras, Rio de \\ Janeiro; 'Department of Neurology, \\ Antônio Pedro University Hospital, \\ Fluminense Federal University, Niterói; \\ 7Biomedical Sciences stricto sensu, \\ Federal University of Piauí; ${ }^{8}$ Fluminense \\ Federal University Medical School, \\ Niterói; 9 Movement Disorders Unit, \\ Antônio Pedro University Hospital, \\ Fluminense Federal University, Niterói; \\ ${ }^{10}$ Brain Mapping and Plasticity \\ Laboratory, ${ }^{11}$ Brain Mapping and \\ Functionality Laboratory, Federal \\ University of Piauí, Parnaíba; 12Brain \\ Mapping and Sensory Motor Integration, \\ Institute of Psychiatry of Federal \\ University of Rio de Janeiro; 13 Institute \\ of Applied Neuroscience, Rio de Janeiro, \\ Brazil
}

\section{Abstract}

Posture is a complex sensory-motor behavior that can be influenced by the fear of falling (FoF) during environmental changes. The aim of this paper is to investigate the influence of FoF on orthostatic postural control in healthy individuals by a systematic review. Thirteen articles were selected. Some other articles (31 references) were used to contextualize and discuss the topic. Studies in the environment made changes on the environment, in which participants were positioned in high hydraulic platforms at different heights, showed a decrease in the center of pressure in the anteroposterior oscillation where the platform was higher. This change in postural control strategy and the FoF are correlated. It can modulate the activity of the muscle spindle $(\mathrm{H}$ reflex) and probably induce postural freezing phenomenon (anticipated postural anxiety). We can conclude that further studies are needed to understand the physiological mechanisms involved in FoF and its relation to changes in postural control strategy.

\section{Introduction}

Postural control is a complex sensory-motor behavior, mediated by visual, vestibular and proprioceptive systems. ${ }^{1-7}$ This is the ability to control the body's position in space with dual purpose of stability and guidance in relation to body segments and the environment. $1,5,6$ Initially, it was believed that the postural control was a highly automated sensory-motor task 1,8 However, with the advances in neuroimaging techniques, it was possible to demonstrate the involvement of the cerebral cortex in postural adjustment in voluntary responses. ${ }^{9}$ Thus, postural control involves changes in the sensory and motor systems in response to postural changes according to the context, ${ }^{1,8}$ based on previous experience and learning. ${ }^{6}$ Given these changes, it is necessary that the postural control system manages anticipatory responses, in order to avoid the imbalance arising from disturbances promoted by a voluntary movement or changes in the environment. 3,5

Some environmental changes seem to be able to induce immediate postural shifts. Studies have investigated the positioning of individuals at high hydraulic platforms at different heights (postural threat levels) and correlated the fear of falling ( $\mathrm{FoF}$ ) with changes in postural control.10-18 Recently, it has been proposed that this type of fear can increase the risk of falling in the elderly, ${ }_{19}$ or in people with chronic obstructive pulmonary disease. ${ }^{20}$ The FoF consists of a psycho-emotional response to a previous event and it is associated with behavioral manifestations, 15 anxiety and fitness level when the participant has to perform a task. ${ }^{21}$ Falls in the elderly have high prevalence (from $29 \%$ to $77 \%)^{22}$ and high costs (between $\$ 0.2$ and $\$ 19$ billion dollars) depending on the event fatality degree. ${ }^{23}$

The etiology of falls is varied and changes in the environment (such as the different heights) are important factors to be considered. Work on the theme proposed in this study are scarce (Supplementary Table S1 and Figure 1), but they are part of the daily context in the multidisciplinary health. Although the fall is a common event, little is known about how the this apprehensiveness may influence postural control and provide the fall and its consequences. ${ }^{19}$ Thus, the aim of this study
Correspondence: Nélio Silva de Souza, University Center Serra dos Órgãos, Av. Rotariana, s/n, Soberbo, Teresópolis, RJ 25960-602, Brazil.

E-mail: neliosds@gmail.com

Key words: Fear of falling; postural control.

Contributions: the authors contributed equally

Conflict of interest: the authors declare no potential conflict of interest.

Received for publication: 5 June 2015.

Revision received: 2 August 2015.

Accepted for publication: 12 November 2015.

This work is licensed under a Creative Commons Attribution NonCommercial 3.0 License (CC BYNC 3.0).

(C) Copyright N.S. de Souza et al., 2015

Licensee PAGEPress, Italy

Neurology International 2015; 7:6057

doi:10.4081/ni.2015.6057

was to investigate, by literature review, the influence of FoF on orthostatic postural control in healthy individuals.

\section{Materials and Methods}

This study is characterized by a systematic review and aims to synthesize and critically evaluate the available evidence on the theme.

\section{Searching the database}

This review used articles indexed in the following databases: PubMed/Medline; Cochrane Central; BIREME and Scholar google, using the key words: fear of falling and postural control. The articles specifically related to the subject include the search period from 1991 to 2011 and are summarized on Supplementary Table S1. During the research did not find any article related to the theme was found in the 2012 to 2015 period (Figure 1). The other articles used for the contextualization and discussion of the topic, include a broader search period (19762015).

\section{Participants, interventions and exclusion criteria}

Studies evaluating individuals without neurological and/or orthopedic injuries that affected their balance using a force platform (stabilometry) for the analysis of orthostatic postural control were included. Exclusion criteria were studies using only scales to measure balance and/or individuals evaluated in clinical conditions such as stroke, Parkinson's disease and multiple sclerosis since the purpose of this 
study is to understand how the FoF only modulates postural control in healthy individuals.

\section{Results}

In total, 13 articles from 1991 to 2011 were selected on FoF and orthostatic postural control in healthy individuals (Figure 1). To date, there are no articles covering a more recent period (2010-2015). All these 13 selected studies are observational cross-sectional and the Supplementary Table S1 summarizes the sample, methodology, results and conclusion of each of them. Only one study, ${ }^{21}$ did not consider the postural balance, but was included to detail their important contribution to the evidence of modulation effects of anxiety on the spinal reflex in healthy individuals, because this study may help in understanding part of the mechanism involved in the FoF and postural control.

\section{Discussion}

\section{Postural orthostatic control}

By definition, center of mass (CoM) total is the relative position where the whole body matter is concentrated. The center of gravity
(CoG) of a body is the vertical projection of its CoM. ${ }^{24}$ The center of pressure $(\mathrm{CoP})$ is defined as the point of application of the ground reaction forces. This is the combination of neuromuscular responses applied to the feet base of support (area in contact with the ground), as well as the displacements of the CoG. ${ }^{24}$ The human body is in constant motion due to continued acceleration around its CoM. ${ }^{25}$ For the maintenance of postural control in the standing position, the central nervous system (CNS) manages the neuromuscular changes to the axial level (head, neck and trunk) and appendicular (ankles, knees, hips and upper limbs), promoting changes in the $\mathrm{CoP}$ so the $\mathrm{CoM}$ remains within the support base limits. ${ }^{24-26}$

\section{Posturography}

Posturography is the study of posture control technique that measures the body displacement, and can be declared as an indicator of the ability to maintain postural stability. 27 This method has been considered reproducible, reliable and valid.28-30 The force platform (or stabilometry) is the posturography instrument used to analyze body movements (changes in the $\mathrm{CoP}$ and $\mathrm{CoG}$ ) for the maintenance of postural control. This equipment usually has four pressure transducers (piezoelectric), monitoring the forces in the vertical direction (z-axis) and horizontal in the anteroposterior direction (AP) (y-axis) and mediallateral (ML) (x-axis). ${ }^{27}$ Postural control in the standing position was studied by theoretical models (biomechanical), which associated the body displacement with the behavior of an inverted pendulum. ${ }^{31,32}$ By comparing this model of inverted pendulum with posturography, it has been suggested that postural movements in humans can occur, mainly from the interaction between the $\mathrm{CoG}$ and the $\mathrm{CoP}, 33$ because changes in neuromuscular control during an adjustment postural changes are reflected in the amplitude of displacement of the CoP. ${ }^{34}$ Thus, especially CoP displacements will be discussed in the context proposed in this study.

\section{The fear of falling and its influence on postural control orthostatic}

The FoF can influence the orthostatic postural control strategy. ${ }^{16}$ Fear consists of a psycho-emotional response to a previous event, which can modulate the reflex activity of the muscle spindle, ${ }^{21}$ and influence the anticipatory postural control ${ }^{14}$ in threatening situations (different heights) $10,13,16-18,35$ or functional (one-leg and bipedal support). ${ }^{36-38}$ By comparing elderly subjects with young adults, postural response (amplitude reduction in $\mathrm{CoP}$ ) to the phobia mentioned before in postural threatening situations (different heights) occurred regardless of age. ${ }^{15}$ However, a group of elderly individuals who had FoF (fear) compared with another group of elderly who had no FoF (nofear), the first group showed less displacement

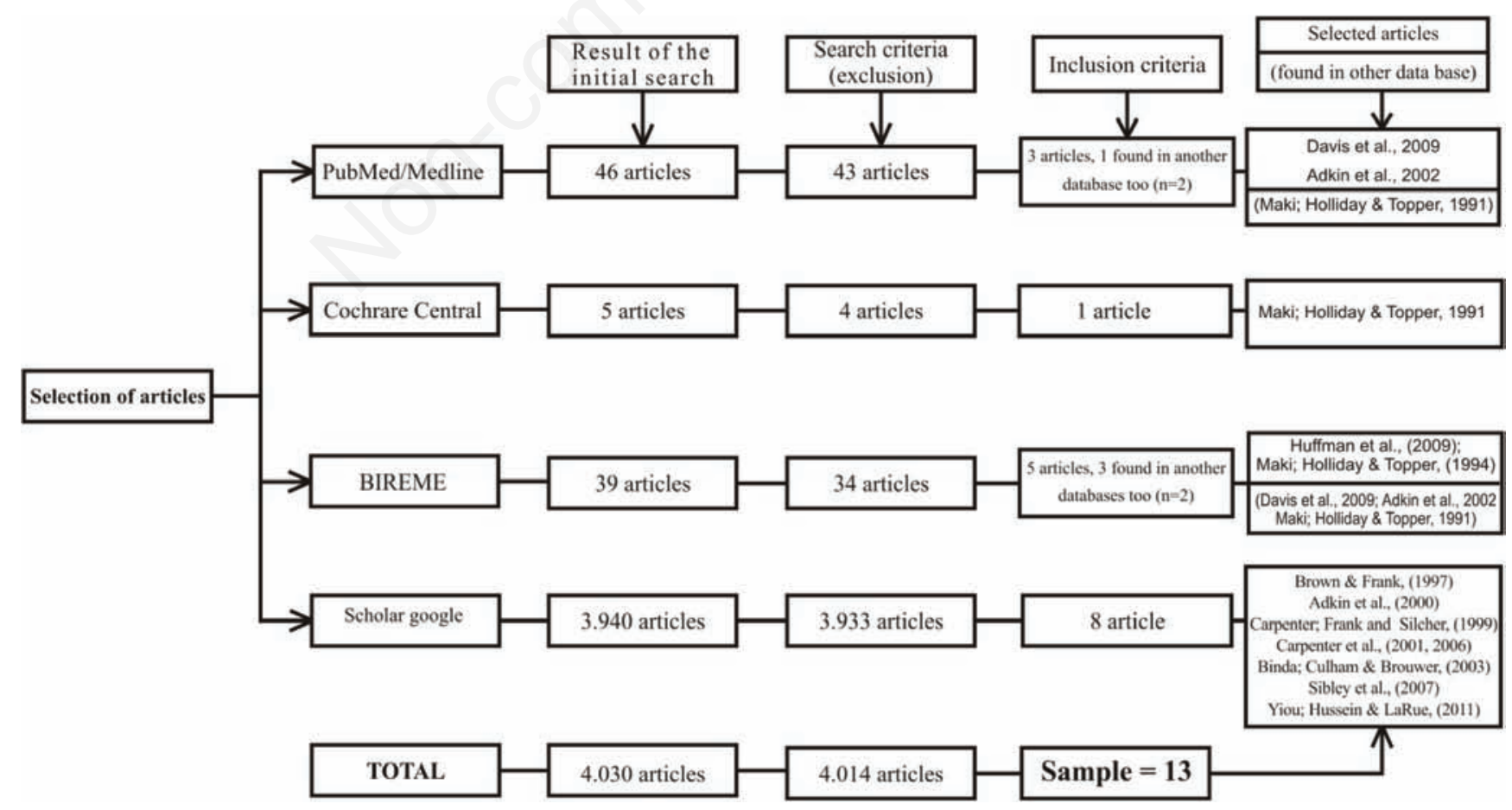

Figure 1. Flowchart of the databases used in our research. 
of the CoP AP and ML directions, compared with the second group. ${ }^{17}$ It seems that the visual condition (especially with open eyes) is important in these threatening situations ${ }^{13,35}$ and it can influence postural control, 16 modulating anxiety levels and postural balance in the condition of high postural threat levels (elevated platform), compared with the average threat levels and/or low (closer to the ground platform). $13,16,35$

The influence of these postural threat levels on postural control was investigated (Supplementary Table S1). In one of these studies, ${ }^{13}$ participants were positioned on the force platform in 3 postural threat levels (different heights): i) low (40 cm); ii) average $(100 \mathrm{~cm})$ and iii) high $(160 \mathrm{~cm})$, with eyes open for 120 seconds (s). The study showed that there is a decrease in the amplitude and frequency of $\mathrm{CoP}$ displacement in the AP direction as it increases the level of postural threat (elevated platform). ${ }^{13}$ This decrease in postural sway is probably related to postural freezing phenomenon, ${ }^{39-41}$ which is observed in participants who view unpleasant images (mutilated or people in pain). ${ }^{39-41}$ It seems that these changes represent a kind of anticipatory anxiety posture, ${ }^{42,43}$ which in this case was induced threatening situation, in which the platform was elevated platform at different heights.

Most studies showed that there is a decrease in the amplitude of oscillation in the CoP AP sense in conditions of high threat levels (elevated platform),12,14,15,17,18,35 which could lead to imminent risk of falling 19 due to immediate change in postural control strategy. ${ }^{16}$ It seems that these findings are more evident in eyes open condition (observing danger) compared with the conditions of closed or blindfolded. 35 These changes were related to modulations in the electromyographic (EMG) activity of the leg muscles (anterior and posterior tibialis and gastrocnemius), $, 12,35$ since the postural anxiety in conditions of postural threat (different heights) can modulate the H-reflex of the gastrocnemius, ${ }^{21}$ reducing the oscillation towards AP,12,14,35 thus facilitating the removal of the threatening stimulus. ${ }^{44}$

The influence of FoF at different heights on the anticipatory postural control during the previous movement (bilateral plantar flexion) was investigated. 14 The study showed that the EMG activity of leg muscles during the proposed motion was modified according to the different heights of the force platform. These changes were correlated with the increase in anxiety levels (changes in skin conductance) and postural instability (changes in the peak of CoP displacement) during the previous movement (bilateral plantar flexion) in each experimental condition (different platform elevations).14 This effect was probably due to the this effect was probably due to the patient's lack of confidence in moving the body earlier (in the sense of postural threat) for the proposed movement, influencing the neuromuscular activity of the gastrocnemius 21 and modulating the postural control strategy on bipedal support 36,37 with open eyes (being aware of the danger). ${ }^{35}$

\section{Conclusions}

To date, there is little evidence about the FoF and its effect on orthostatic postural control and postural anticipatory anxiety in healthy subjects. It seems that there is a postural freezing phenomenon in postural threat conditions (elevated platform) and it is observed when viewing unpleasant or threatening images. The fall event is common in the elderly and may have fatal consequences. Therefore, it seems crucial to understand this phobia, which can lead to an anxiogenic event and facilitate the fall due to changes in anticipatory posture control strategy. Further studies are needed to understand the psycho-emotional mechanisms involved in both changes in body posture (relative position of body parts) and postural control (changes in the CoP and/or CoG), in order to direct its early diagnosis, prevention and neuro-orthopedic medical treatment conditions that can be presented with changes in postural control.

\section{References}

1. Horak FB. Clinical measurement of postural control in adults. Phys Ther 1987;67: 1881-5.

2. Fitzpatrick R, McCloskey DI. Proprioceptive, visual and vestibular thresholds for the perception of sway during standing in humans. J Physiol 1994;478:173-86.

3. Massion J. Postural control systems in developmental perspective. Neurosci Biobehav Rev 1998;22:465-72.

4. Redfern MS, Yardley L, Bronstein AM. Visual influences on balance. J Anxiety Disord 2001;15:81-94.

5. Massion J. Movement, posture and equilibrium: interaction and coordination. Prog Neurobiol 1992;38:35-56.

6. Horak FB. Postural orientation and equilibrium: what do we need to know about neural control of balance to prevent falls? Age Ageing 2006;35:7-11.

7. Ciríaco JG, Alexandre PL, Pereira CB, et al. Vertigem postural fóbica. Arq Neuro-psiquiatr 2004;62:669-73.

8. Nashner LM. Brain adapting reflexes controlling the human posture. Exp Brain Res 1976;26:59-72.

9. Mihara M, Miyai I, Hatakenaka M, et al. Role of the prefrontal cortex in human balance control. Neuroimage 2008;43:329-36.

10. Brown LA, Frank JS. Postural compensations to the potential consequences of instability: kinematics. Gait Posture 1997;6: 89-97.

11. Carpenter MG, Frank JS, Silcher CP. Surface height effects on postural control: a hypothesis for a stiffness strategy for stance. J Vestib Res 1999;9:277-86.

12. Carpenter M, Frank J, Silcher C, Peysar G. The influence of postural threat on the control of upright stance. Exp Brain Res 2001;138:210-8.

13. Adkin AL, Frank JS, Carpenter MG, Peysar GW. Postural control is scaled to level of postural threat. Gait Posture 2000;12:87-93.

14. Adkin AL, Frank JS, Carpenter MG, Peysar GW. Fear of falling modifies anticipatory postural control. Exp Brain Res 2002;143: 160-70.

15. Carpenter M, Adkin AL, Brawley LR, Frank JS. Postural, physiological and psychological reactions to challenging balance: does age make a difference? Age Ageing 2006; 35:298-303.

16. Davis JR, Campbell AD, Adkin AL, Carpenter MG. The relationship between fear of falling and human postural control. Gait Posture 2009;29:275-9.

17. Binda SM, Culham EG, Brouwer B. Balance, muscle strength, and fear of falling in older adults. Exp Aging Res 2003; 29:205-19.

18. Huffman JL, Horslen BC, Carpenter MG, Adkin AL. Does increased postural threat lead to more conscious control of posture? Gait Posture 2009;30:528-32.

19. Young WR, Mark Williams A. How fear of falling can increase fall-risk in older adults: Applying psychological theory to practical observations. Gait Posture 2015;1:7-12

20. Oliveira CC, McGinley J, Lee AL, et al. Fear of falling in people with chronic obstructive pulmonary disease. Respir Med 2015;1-7.

21. Sibley KM, Carpenter MG, Perry JC, Frank JS. Effects of postural anxiety on the soleus H-reflex. Hum Mov Sci 2007;26:103-12.

22. Hadjistavropoulos T, Delbaere K, Fitzgerald TD. Reconceptualizing the role of fear of falling and balance confidence in fall risk. $\mathrm{J}$ Aging Health 2011;23:3-23.

23. Stevens JA, Corso PS, Finkelstein EA, Miller TR. The costs of fatal and non-fatal falls among older adults. Inj Prev 2006;12: 290-5.

24. Winter DA. Human balance and posture standing and walking control during. Gait Posture 1995;5:193-214.

25. Günther M, Putsche P, Leistritz L, Grimmer S. Phase synchronisation of the three leg joints in quiet human stance. Gait Posture 2011;33:412-7. 
26. Zatsiorsky VM, King DL. An algorithm for determining gravity line location from posturographic recordings. J Biomech 1998; 31:161-4.

27. Monsell EM, Furman JM, Herdman SJ, et al. Computerized dynamic platform posturography. Otolaryngol Neck Surg 1997;117: 394-8.

28. Doyle RJ, Hsiao-Wecksler ET, Ragan BG, Rosengren KS. Generalizability of center of pressure measures of quiet standing. Gait Posture 2007;25:166-71.

29. Doyle TL, Newton RU, Burnett AF. Reliability of traditional and fractal dimension measures of quiet stance center of pressure in young, healthy people. Arch Phys Med Rehabil 2005;86:2034-40.

30. Santos BR, Delisle A, Larivière $\mathrm{C}$, et al. Reliability of centre of pressure summary measures of postural steadiness in healthy young adults. Gait Posture 2008;27:408-15.

31. Winter DA, Patla AE, Prince F, et al. Stiffness control of balance in quiet standing. J Neurophysiol 1998;80:1211-21.

32. Gage WH, Winter DA, Frank JS, Adkin AL.
Kinematic and kinetic validity of the inverted pendulum model in quiet standing. Gait Posture 2004;19:124-32.

33. Maurer C, Peterka RJ. A new interpretation of spontaneous sway measures based on a simple model of human postural control. J Neurophysiol 2005;93:189-200.

34. Önell A. The vertical ground reaction force for analysis of balance? Gait Posture 2000;12:7-13.

35. Carpenter M, Frank JS, Silcher CP. Surface height effects on postural control: a hypothesis for a stiffness strategy for stance. J Vestib Res 1999;9:277-86.

36. Maki BE, Holliday PJ, Topper AK. A prospective study of postural balance and risk of falling in an ambulatory and independent elderly population. J Gerontol 1994; 49:72-84.

37. Maki BE, Holliday PJ, Topper AK. Fear of falling and postural performance in the elderly. J Gerontol 1991;46:123-31.

38. Yiou E, Hussein T, LaRue J. Influence of temporal pressure on anticipatory postural control of medio-lateral stability during rapid leg flexion. Gait Posture 2011;35: 494-9.

39. Azevedo TM, Volchan E, Imbiriba LA, et al. A freezing-like posture to pictures of mutilation. Psychophysiology 2005;42:255-60.

40. Lelard T, Montalan B, Morel MF, et al. Postural correlates with painful situations. Front Hum Neurosci 2013;7:4.

41. D’Attilio M, Rodolfino D, Abate M, et al. Effects of affective picture viewing on postural control in healthy male subjects. Cranio J Craniomandib Pract 2013;31:202-10.

42. Ishida M, Saitoh J, Wada M, Nagai M. Effects of anticipatory anxiety and visual input on postural sway in an aversive situation. Neurosci Lett 2010;474:1-4.

43. Levitan MN, Crippa JA, Bruno LM, et al. Postural balance in patients with social anxiety disorder. Brazilian J Med Biol Res 2012;45:38-42.

44. Eerland A, Guadalupe TM, Franken IHA, Zwaan RA. Posture as index for approachavoidance behavior. PLoS One 2012;7: e31291. 